\title{
Derecho Corporativo y de Libre Competencia
}

José Antonio Gaspar

Profesor de Derecho Comercial y Derecho Civil

Universidad Diego Portales

Fernando Araya Jasma

Profesor de Derecho Comercial Universidad Diego Portales

\section{Derecho Corporativo}

Motivación DE LA SOliCitud DE ACCIONISTAS PARA CITAR A JUNTA DE ACCIONistas. Delimitación De facultades DE ADMINISTRACIÓN DEL DIRECTORIO Y DE La JunTa DE aCCIONistas. SuperINTENDENCIA DE VALORES Y SEGUROS, OFICIO ORDINARIO N $\mathrm{N}^{\mathrm{O}} 2827 \mathrm{DE} 18 \mathrm{DE}$ FEBRERO DE 2010 Y OFICIO ORDINARIO $\mathrm{N}^{\mathrm{O}} 3209$ DE 26 DE FEBRERO DE $2010^{1}$

Para que un mercado de capitales sea competitivo, se necesita que todos los accionistas de una sociedad anónima puedan ejercitar sus derechos políticos mediante los órganos contemplados al efecto, en especial a través de la junta de accionistas.

Pero dichos derechos deben conciliarse con la estructura de administración propia de la sociedad

${ }^{1}$ El comentarista de esta jurisprudencia administrativa agradece el apoyo de la ayudante del departamento de Derecho de la Empresa y Laboral de la Facultad de Derecho de la Universidad Diego Portales, Xaviera Gardella, en la obtención y análisis de la documentación que se comenta. anónima, que es establecida por la ley.

En tal sentido, una operación de M\&A fue objeto de dos pronunciamientos de la Superintendencia de Valores y Seguros, que ahora comentamos.

1. Mediante hecho esencial de fecha 10 de febrero de 2010, CAP informó al mercado la operación que pretendía realizar con MCI, filial de Mitsubishi Corporation, para que MCI fuera accionista de la CMP. Esta operación consistiría

(i) en la fusión por absorción de la $\mathrm{CMH}$, de la cual MCI ya era propietaria de un $50 \%$, y mediante tal fusión MCI recibiría el 15,9\% de las acciones de CMP y

(ii) en un aumento de capital de CMP, por cuya suscripción MCI incrementaría su participación directa a un 25\% del capital pagado de CAP.

En el mismo hecho esencial, CAP hizo presente que citaría a junta extraordinaria de accionistas para ratificar esta operación con MCI.

A su vez, INVERCAP S.A. era dueña del 31,32\% de CAP, partici- 
pación que representaba el principal activo de su patrimonio. Tres de los siete directores de INVERCAP solicitaron por escrito al presidente del directorio de INVERCAP, primero en su calidad de directores, y luego como representantes de accionistas de INVERCAP, que citase a una junta extraordinaria de accionistas de INVERCAP para que dicha junta determinase la forma en que INVERCAP votaría en la junta extraordinaria de accionistas de CAP, convocada para ratificar la operación con MCI. Esto, de conformidad al artículo $58 \mathrm{~N}^{\mathrm{o}} 3$ de la ley $\mathrm{N}^{\mathrm{o}} 18.046$, sobre Sociedades Anónimas, que dispone que el directorio de una sociedad anónima debe convocar a junta ordinaria o extraordinaria, citen accionistas que representen, a lo menos, el 10\% de las acciones emitidas con derecho a voto, expresando en la solicitud los asuntos a tratar en la junta.

El presidente del directorio de INVERCAP consideró que la decisión sobre cómo debiese votar esta sociedad en la junta extraordinaria de accionistas de CAP correspondía al directorio de INVERCAP, en el marco de las atribuciones de dirección y administración del directorio, conforme al artículo 40 de la Ley de Sociedades Anónimas. Por ello, la solicitud de los accionistas de citar a junta extraordinaria de accionistas de INVERCAP para pronunciarse sobre esta materia, sustraería del directorio de INVERCAP la facultad para decidir sobre la misma que le otorga la ley. Agregó que una limitación de las atribuciones del directorio requería una reforma de estatutos conforme al artículo $67 \mathrm{~N}^{\mathrm{O}}$ 7 de la Ley de Sociedades Anónimas. Finalizó señalando que el derecho contemplado a los accionistas en el artículo 58 No 3 de la Ley de Sociedades Anónimas para solicitar que se citase a junta extraordinaria de accionistas no se podía ejercer de modo que dejase sin aplicación las normas imperativas de la misma ley sobre atribuciones del directorio y el modo de establecer limitaciones a las atribuciones del directorio, antes señaladas.

Ante la negativa del presidente del directorio, los directores solicitantes, en su calidad de directores y accionistas de INVERCAP expusieron estos hechos a la Superintendencia de Valores y Seguros, quien dio traslado de dicha presentación a INVERCAP, cuyo gerente general respondió en los mismos términos que ya lo había hecho el presidente del directorio.

2. Analizados los antecedentes, la Superintendencia de Valores y Seguros estimó que la operación que iba a realizarse en CAP era de relevancia y de interés social para los accionistas de INVERCAP, conforme a los términos del $\mathrm{N}^{\mathrm{O}} 4$ del artículo 56 de la Ley de Sociedades Anónimas, que incluye como materia de junta ordinaria de accionistas
"cualquier materia de interés social que no sea propia de una junta extraordinaria". 
A lo anterior, la Superintendencia agregó:

"De otro lado, el artículo 58 $\mathrm{N}^{\mathrm{O}}$ 3) de la Ley 18.046, indica que el directorio 'deberá' convocar A junta ordinaria o extraordinaria, según sea el caso, cuando así lo soliciten accionistas que representen, a lo menos el 10\% de las acciones emitidas con derecho a voto, expresando en la solicitud los asuntos a tratar en la junta. De lo expuesto se puede colegir, de acuerdo al tenor literal de la disposición legal, la celebración de la junta de accionistas ha sido solicitada cumpliendo con los requisitos y condiciones que la misma disposición legal señala, esto es, que sea solicitada por el $10 \%$ de las acciones emitidas con derecho a voto, expresando en la solicitud los asuntos a tratar, los que corresponde a materias de interés social".

Con ello, la Superintendencia de Valores y Seguros, mediante el oficio ordinario $\mathrm{N}^{\mathrm{o}} 2827$ de 18 de febrero de 2010, requirió al presidente del directorio de INVERCAP para que citase a junta extraordinaria de accionistas en que fuese informada y se adoptara una decisión sobre la conveniencia para los intereses sociales de INVERCAP de las negociaciones que se encontraba efectuando CAP con MCI respecto de CMP, dentro del plazo contemplado en el inciso final del artículo 58 de la Ley de Sociedades Anónimas.

3. Atendido el requerimiento de la Superintendencia, el directorio de INVERCAP acordó citar a junta extraordinaria de accionistas de INVERCAP para el día 10 de marzo de 2010, conforme se informó mediante hecho esencial de fecha 22 de febrero de 2010.

Adicionalmente, el presidente del directorio de INVERCAP solicitó al ente regulador que precisase que el requerimiento de citar a junta extraordinaria de accionistas de INVERCAP para tratar el tema antes señalado, no limitaba las atribuciones del directorio para determinar la forma en que INVERCAP debía votar en la junta extraordinaria de accionistas de CAP, sino que el pronunciamiento de los accionistas de INVERCAP sólo sería un antecedente no vinculante para que el directorio de INVERCAP resolviese lo que correspondiese.

$\mathrm{Al}$ respecto, la Superintendencia de Valores y Seguros, mediante oficio ordinario $\mathrm{N}^{\mathrm{o}} 3209$ de 26 de febrero de 2010 respondió:

"La Superintendencia a través del Oficio No 2827 de 18 del mes y año en curso, no ha limitado los poderes y atribuciones del directorio. La materia a tratar en la junta de accionistas citada para el día 10 de marzo de 2010, no corresponde a una de aquellas establecida en la ley o en los estatutos como privativa de la junta de accionistas, por lo cual no limita las 
facultades del directorio que establece el artículo 40 de la Ley $\mathrm{N}^{\mathrm{0}} 18.046$ ".

4. Inicialmente, pareciera que mediante los oficios ordinarios $\mathrm{N}^{\mathrm{O}}$ 2827 y 3209 del año 2010, la Superintendencia de Valores y Seguros habría adoptado decisiones contradictorias al permitir que los accionistas de INVERCAP forzasen la citación a junta extraordinaria para pronunciarse sobre la conveniencia de las negociaciones de CAP y MCI, pero sin que dicho pronunciamiento fuese vinculante para el directorio de INVERCAP. Pero esta apreciación debe ser revisada porque en estos dos dictámenes se pueden distinguir distintas materias, no contradictorias,

- Que los accionistas que representen al menos el 10\% de las acciones emitidas con derecho a voto pueden solicitar que se cite a junta de accionistas siempre que sea para alguna materia propia de junta de accionistas. En tal sentido, basta la materia de la citación a Junta pueda ser considerada como de interés social para que sea entendida como materia de junta de accionistas conforme al $\mathrm{N}^{\mathrm{O}} 4$ del artículo 56 de la Ley de Sociedades Anónimas. La Superintendencia aclara esta facultad de los accionistas y permite su ejercicio sin que pueda afectarse por eventuales contraposiciones de atribuciones

entre los órganos sociales, lo que resuelve a continuación.

- Que corresponde al directorio la administración de una sociedad anónima, no pudiendo ser limitadas sus atribuciones a este respecto, sino por ley o cláusula estatutaria. Así, el mero hecho que la junta de accionistas pueda conocer $y$ pronunciarse sobre una materia de interés social no limita las atribuciones de administración del directorio, salvo los casos anteriores, de modo que en situaciones como la que se comenta, la decisión de la junta de accionistas no sería vinculante para el directorio. En el mismo sentido ${ }^{2}$, en cuanto a que las atribuciones de la junta de accionistas son limitadas por las materias que la ley o los estatutos reservan a otros órganos sociales, en especial las facultades de administración y representación que la ley radica en el directorio.

- Que, en definitiva, sí puede citarse a junta de accionistas para que ella emita un pronunciamiento no vinculante a la administración de la sociedad anónima. De este modo, aunque se discuta la utilidad o conveniencia práctica, podría citarse a junta de accionistas con el propósito principal de

2 Álvaro Puelma Accorsi, Sociedades, Santiago, Editorial Jurídica de Chile, 2009, tomo II, pp. 657. 
que los accionistas puedan "informarse" sobre un negocio que sea de interés social. Así, la posibilidad de citar a junta de accionistas no se ve limitada a obtener pronunciamientos vinculantes para con la administración, sino también como una forma de los accionistas para obtener información de interés social a la que de otra manera no podrían tener acceso.

5. Cabe agregar en este caso que, después de los pronunciamientos antes expuestos de la Superintendencia, el comité de directores de INVERCAP se reunió el 4 de marzo de 2010, determinando que la transacción entre CAP y MCI respecto de CMP y CMH constituía una operación entre partes relacionadas para INVERCAP, dado que consideraban que INVERCAP, CAP y $\mathrm{CMH}$ formaban parte del mismo grupo empresarial, siendo personas relacionadas, lo mismo que $\mathrm{CMP}$ en el sentido de coligada. Tal pronunciamiento tenía por objetivo que se aplicasen los nuevos requisitos y procedimientos para las operaciones con partes relacionadas en las sociedades anónimas abiertas y filiales incorporado por la ley $\mathrm{N}^{\circ} 20.382$, sobre Gobiernos Corporativos como nuevo título Xvi de la Ley de Sociedades Anónimas. Esta situación fue planteada por un accionista de INVERCAP a la Superintendencia de Valores y Seguros, para que ordenase al directorio de INVERCAP suspender la celebración de la junta extraordinaria de accionistas con- vocada para el 10 de marzo de 2011 y requiriese que el directorio de INVERCAP citase a junta extraordinaria de accionistas de INVERCAP conforme al artículo 147 de la Ley de Sociedades Anónimas para que sometiese a su decisión la aprobación de la operación entre CAP y MCI por $\operatorname{los}_{2} 2 / 3$ de las acciones con derecho a voto de INVERCAP.

La Superintendencia dio traslado de esta nueva solicitud al presidente de INVERCAP, quien solicitó una extensión de plazo para responderlo, lo que en definitiva realizó el 15 de marzo de 2010, rechazando la solicitud. En tal sentido, afirmó que para que una operación sea considerada como operación con parte relacionada no basta la declaración del comité de directores cuando en dicha operación no interviene la sociedad en cuestión, como era el caso de INVERCAP respecto de la operación entre CAP y MCI.

Cabe agregar que, finalmente, la Junta Extraordinaria de Accionistas de INVERCAP se realizó el 10 de marzo de 2010, informándose sobre la operación entre CAP y MCI, la cual fue considerada como conveniente para INVERCAP por el $58,2 \%$ de los accionistas asistentes a la junta. Asimismo, en este tema no encontramos un pronunciamiento expreso de la Superintendencia de Valores y Seguros ni algún desistimiento de la solicitud pertinente. Lamentamos que la Superintendencia no haya cumplido con el principio de inexcusabilidad contemplado en el artículo 14 de la ley $\mathrm{N}^{\circ} 19.880$, sobre 
Procedimientos Administrativos, que la obliga a dictar resolución expresa en todo procedimiento, cualquiera que sea su forma de iniciación. Más aún, sobre una materia novedosa como es la calificación por un comité de directores de un negocio como operación con parte relacionada de sociedad anónima abierta, para efectos del procedimiento y requisitos contemplados en el nuevo título XVI de la Ley de Sociedades Anónimas.

\section{BibLIOGRAFÍA}

Puelma Accorsi, Álvaro, Sociedades, Santiago, Editorial Jurídica de Chile, 2009.
EXTENSIÓN DE LA OBLIGACIÓN DE DILIGENCIA Y CUIDADO DE LOS DIRECTORES DE SOCIEDADES ANÓNIMAS. Superintendencia de Valores Y Seguros, Resoluciones EXENTAS $\mathrm{N}^{\circ}$ $854,855,859,860,861$, TODAS DE 31 DE DICIEMBRE DE $2009^{3}$

Como señala Álvaro Puelma Accor$\mathrm{si}^{4}$, para el debido ejercicio de los

${ }^{3} \mathrm{El}$ comentarista de esta jurisprudencia administrativa agradece el apoyo de la alumna del magíster de Derecho Civil Patrimonial de la Facultad de Derecho de la Universidad Diego Portales, Angélica Bermúdez, en el análisis de la documentación que se comenta.

${ }^{4}$ Álvaro Puelma Accorsi, Sociedades, Santiago, Editorial Jurídica de Chile, 2009, tomo II, p. 635. deberes de director de una sociedad anónima, se requiere estar plenamente informado de los antecedentes sociales y los negocios de ésta. Pero este derecho también reviste el carácter de un deber, habiendo la Superintendencia de Valores y Seguros precisado su extensión en una sociedad anónima abierta, en el marco del reciente caso de colusión de las farmacias.

1. En los dictámenes contenidos en las resoluciones exentas $\mathrm{N}^{\circ} 854$, $855,859,860,861$, todas de 31 de diciembre de 2009, la Superintendencia de Valores y Seguros consideró que se pudieron determinar los siguientes hechos:

Durante el año 2008, FASA fue objeto de un proceso de investigación iniciado por la FNE relativo a una posible concertación de precios en diversos medicamentos de las principales cadenas farmacéuticas. En tal sentido, el 9 de diciembre de 2008, la FNE presentó un requerimiento contra FASA ante el TDLC, bajo el rol C-184-08. Este requerimiento y sus fundamentos fueron analizados por el directorio de FASA en su sesión de 18 de diciembre de 2008, habiendo previamente contratado a una abogada especialista para este tema.

Durante el mes de diciembre de 2008, se inició una investigación interna de FASA destinada a establecer la efectividad del requerimiento de la FNE. Con los primeros resultados de la investigación interna de FASA, el 13 de enero de 2009 se iniciaron conversaciones entre la FNE y FASA 
en orden a llegar a un acuerdo de conciliación, siendo FASA representada por Alejandro Rosemblatt. Durante dicho proceso, el 15 de enero de 2009, el vicepresidente ejecutivo de FASA, Alejandro Rosemblatt, informó al presidente del directorio de FASA, José Codner, de la investigación interna que llevaba la compañía, en que se habría establecido que determinados ejecutivos se habrían coludido, y que se encontraba negociando un posible acuerdo conciliatorio con la FNE.

El 16 de enero de 2009, José Codner citó a los directores de FASA a sesión extraordinaria a celebrarse el 20 de enero de 2009, para tratar como único tema la información sobre el requerimiento de la FNE, sesión que no se celebró por falta de quórum. Por ello, el 19 de enero de 2009, José Codner citó nuevamente a los directores de FASA a sesión extraordinaria para el 23 de enero de 2009, para tratar el mismo tema, sesión que tampoco se celebró, porque fue suspendida por José Codner.

El 23 de enero de 2009, la FNE y FASA, representada ésta última por su fiscal corporativo Sergio Mesías, firmaron un preacuerdo de conciliación. Después de ello, los días 29 de enero, 26 de febrero y 2 de marzo, se celebraron sesiones ordinarias de directorio de FASA, sin que existiese ninguna constancia en actas que se hubiese tratado, informado ni consultado acerca de las materias vinculadas a la investigación interna, el requerimiento de la FNE ni sobre la negociación para el acuerdo conci- liatorio. Más aún, en la sesión del comité de directores del 26 de febrero de 2009 y en la sesión de directorio del mismo día, se revisó y aprobó la FECU de FASA correspondiente al 31 de diciembre de 2008, en cuya nota $\mathrm{N}^{\circ} 21$ de las contingencias, se indicaba que el requerimiento de la FNE no debiera prosperar en la forma planteada.

El 13 de marzo de 2009, FASA, representada por Sergio Mesías, y la FNE firmaron el acuerdo conciliatorio. Tras ello, el 20 de marzo de 2009, el Fiscal Nacional y el jefe de la división económica de la FNE se reunieron con Alejandro Rosemblatt para revisar detalles del acuerdo suscrito. Finalmente, el 23 de marzo de 2009, se presentó el acuerdo conciliatorio ante el TDLC, y se informó de él en sesión extraordinaria de directorio de FASA celebrada el mismo día.

2. Sobre la base de los hechos antes referidos, la Superintendencia de Valores y Seguros estableció cómo los integrantes del directorio de FASA ejercieron sus cargos y los derechos y obligaciones que de ellos se derivan, en el período desde que se tuvieron noticias de una posible concertación de precios en ciertos medicamentos, hasta la firma y presentación ante el TDLC del acuerdo conciliatorio entre FASA y la FNE, que puso fin a la investigación iniciada por la FNE al respecto.

En dicho contexto, la Superintendencia formuló cargos contra los directores: Juan Cúneo, Eduardo Bellinghausen, Juan Benavides, Alexander Fernández, Jaime Sinay, 
Gabriel Berczely, Pablo Lamarca y Ernesto Labatut, mediante los oficios ordinarios $\mathrm{N}^{\mathrm{o}} 13858,13859,13860$, 13861, 13862, 13863, 13864 y 13865 , respectivamente, todos de 2 de julio de 2009, por no haber recabado información acerca de la situación que afectaba a FASA en relación con la investigación llevada por la FNE, ni haber ejercido las facultades conferidas por el artículo 39 de la Ley de Sociedades Anónimas, en cuanto a procurar encontrarse plenamente informados de todo lo relacionado con la marcha de la empresa, todo ello hasta que tomaron conocimiento del requerimiento de la FNE en contra de FASA y hasta la firma y presentación del acuerdo conciliatorio. Por ello, la Superintendencia estimaba que estos directores no habrían actuado con el cuidado y diligencia que los hombres deben emplear ordinariamente en sus propios negocios al tenor de la exigencia impuesta por el artículo 41 de la Ley de Sociedades Anónimas, todo ello no obstante tratarse de hechos que podrían ser calificados como esenciales conforme la definición del artículo $9^{\circ}$ de la ley $\mathrm{N}^{\mathrm{O}} 18.045$, sobre Mercado de Valores 5 .

${ }^{5}$ Adicionalmente, aunque no son materia de este comentario, agregamos que la Superintendencia formuló cargos en contra de:

- el presidente del directorio de FASA, José Codner, mediante el oficio ordinario $\mathrm{N}^{\mathrm{O}} 13857$ de fecha 2 de julio de 2009, por (i) arrogarse atribuciones propias del directorio, al ser el único director informado por Alejandro Rosemblatt sobre los hechos el 15 de enero de 2009, y haber instruido al mismo a recabar un

Todos estos directores dieron resacuerdo con la FNE y lograr la mejor negociación posible para FASA con dicha entidad. La Superintendencia estimaba que, con ello, José Codner había adoptado decisiones y determinaciones respecto de materias por cuya naturaleza, entidad e influencia en FASA e intereses sociales, resultaban inherentes a la función del directorio, infringiendo lo dispuesto en el artículo 31 y siguientes de la Ley $\mathrm{N}^{\circ} 18.046$, sobre Sociedades Anónimas; (ii) haber omitido proporcionar a los demás directores de FASA antecedentes de suma relevancia para la compañía, vulnerando el esquema y estructura de administración social que define la Ley de Sociedades Anónimas, y entre cuyos pilares, se encuentra la información como base del buen gobierno corporativo y (iii) no haber recabado información sobre la posible concertación de precios en los medicamentos, hasta que tomó conocimiento del requerimiento de la FNE en contra de FASA, pese a la difusión de prensa sobre este tema y el inicio de la investigación por la FNE, de modo que la Superintendencia consideró que José Codner no habría actuado con el cuidado y diligencia que los hombres deben emplear ordinariamente en sus propios negocios al tenor de la exigencia impuesta por el artículo 41 de la Ley de Sociedades Anónimas.

- El vicepresidente ejecutivo de FASA, Alejandro Rosemblatt, mediante el oficio ordinario $\mathrm{N}^{\mathrm{o}} 13866$ de fecha 2 de julio de 2009, por no haber puesto en conocimiento de los directores de FASA -a excepción de José Codner- de los hechos que tras la investigación interna lleva a cabo, daban cuenta de actuaciones colusivas de FASA, que 
puesta a los cargos de la Superinten-

derivaron el necesidad de buscar y firmar un acuerdo de conciliación con la FNE. Ello, pese a que tales hechos podían ser calificados como esenciales al tenor de la definición del artículo $9^{\circ}$ de la Ley de Mercado de Valores. Mediante dicha omisión, la Superintendencia consideró que Alejandro Rosemblatt se había arrogado, junto al presidente del directorio de FASA, atribuciones propias del directorio, adoptando decisiones y determinaciones respecto de una problemática que afectaba a la compañía y que era inherente a la función del directorio. Así, la Superintendencia estimó que Alejandro Rosemblatt habría vulnerado el esquema y estructura de administración social que define la Ley de Sociedades Anónimas y, entre cuyos pilares, se encuentra la información como base del buen gobierno corporativo. Lo anterior además significaba que Alejandro Rosemblatt hacía las veces de gerente general de FASA, y en tal calidad no habría actuado con el cuidado y diligencia que exigía a su respecto el artículo 41 de la Ley de Sociedades Anónimas, en relación con el artículo 50 de la misma ley.

José Codner dio respuesta al oficio 13857 y formuló sus descargos, tras lo cual la Superintendencia de Valores y Seguros, mediante la resolución exenta $\mathrm{N}^{\circ} 858$ de fecha 31 de diciembre de 2009, le aplicó la sanción de multa a beneficio fiscal, ascendente a UF 1.500. José Codner decidió pagar la multa y no impugnar la sanción de la Superintendencia de Valores y Seguros.

Por su parte, Alejandro Rosemblatt dio respuesta al oficio 13866 y formuló sus descargos, tras lo cual la Superintendencia de Valores y Seguros, mediante la resolución dencia de Valores y Seguros, formulando básicamente los siguientes descargos:

- que era un principio aceptado en el ámbito de las sociedades anónimas que sus directores no están encargados de la administración ordinaria y continua de la compañía, sino de su dirección superior. Para tal administración ordinaria y continua, el directorio debería contar con un grupo ejecutivo profesional, competente y confiable, que realizara la función ejecutiva.

- que, por el tamaño de FASA, su directorio necesitaba contar con un equipo consecuente con las necesidades de la compañía, que se hiciera cargo de los innumerables requerimientos y procesos de la autoridad y particulares respecto de FASA.

exenta No857 de fecha 31 de diciembre de 2009, le aplicó la sanción de multa a beneficio fiscal, ascendente a UF 2.000. Alejandro Rosemblatt dedujo acción de reclamación en juicio sumario en contra de la resolución exenta $\mathrm{N}^{\circ} 857$, la cual fue rechazada en primera instancia por el $26^{\circ}$ Juzgado Civil de Santiago, en la causa rol C-17242010, con fecha 22 de octubre de 2010. Dicha sentencia fue apelada por Alejandro. Rosemblatt, estando, a la fecha de este comentario, pendiente su resolución ante la I. Corte de Apelaciones de Santiago, bajo el rol civil 7374-2010. 
- que, respecto de la investigación de la FNE, estos directores sólo contaron con la información que les proporcionaron los ejecutivos principales de FASA, haciendo fe de ellos y de contar con una abogado especialista en el tema, como para sentirse tranquilos.

- que la responsabilidad de los directores se asimilaba a la responsabilidad derivada de culpa o descuido leve, atendiendo al cuidado de un hombre normal y prudente a cargo de sus negocios propios, lo que está vinculado a la previsibilidad o posibilidad de prever un cierto resultado dadas determinadas circunstancias.

- que la conducta de estos directores fue razonable y prudente, al tenor de los hechos e información que se les proporcionó. Estimaban que los cargos de la Superintendencia estarían exigiendo una diligencia imposible de cumplir, sobre la base de hechos posteriores a la sesión de directorio de 23 de marzo de 2009, en que el directorio de FASA tomó conocimiento del acuerdo conciliatorio con la FNE.

- que no hubo negligencia de parte de los directores al hacer fe de la información proporcionada por los ejecutivos de FASA, puesto que en función del principio

de confianza y lealtad con aquéllos, estos directores no estaban obligados a pesquisar, investigar o intuir lo que realmente ocurría, ni suponer que se les ocultaba información. Sólo una vez rota dicha base de confianza y lealtad, procedería otra actitud. Lo contrario, desnaturalizaría la función propia del director, en cuanto lo obligaría a invadir la esfera de la administración ordinaria y corriente de la administración social, volviéndole en verdaderos "investigadores" que deben pesquisar si lo que se les informa se ajusta a la realidad.

- que, en definitiva, los cargos de la Superintendencia no ponderaban la actuación de los ejecutivos principales de FASA, en cuanto a que no sólo no habrían proporcionado información a los directores sobre la investigación de la FNE sino que, además, se les dieron antecedentes no ajustados a la realidad acerca de los avances de dicha investigación, hallazgos y negociaciones con la FNE.

3. La Superintendencia de Valores y Seguros, mediante resoluciones exentas $\mathrm{N}^{\circ} 854,855,859,860$, 861 , todas de fecha 31 de diciembre de 2009, sostuvo que, de los hechos y documentos revisados, no constaba que la posible concertación de precios en ciertos medicamentos de FASA hubiese sido objeto de con- 
sulta, cuestionamiento o evaluación por parte de los directores de FASA. Tampoco habría sido objeto de consulta si tal situación pudiese afectar la situación de la compañía o sus intereses. Lo anterior, sin perjuicio de existir información de pública notoriedad al respecto.

Tampoco los directores recabaron mayor información sobre la investigación de la $\mathrm{FNE}$, pese a la relevancia que mostraba tal investigación por la contratación de una abogada experta en materias de libre competencia. Lo mismo ocurrió respecto del requerimiento de la FNE que les fuera informado en la sesión de directorio de 18 de diciembre de 2008, estimando la Superintendencia que estos directores se limitaron a descansar en lo que se les informaba por los ejecutivos de la compañía.

De este modo, la Superintendencia concluyó que, sin perjuicio que la administración ejecutiva de FASA habría ocultado información a los directores, éstos

"no recabaron información acerca de lo que ocurría no obstante la disposición del artículo 39 de la Ley $\mathrm{N}^{\circ}$ 18.046, que les otorga el derecho, como directores de la sociedad, de estar informados de todos los aspectos relacionados a la marcha de la empresa”.

La Superintendencia precisó:

"que, sin perjuicio que dicha norma se encuentra estable- cida como una facultad de los directores, ésta debe ser entendida bajo la premisa que se trata de un derecho fijado respecto de quien tiene un deber fiduciario con la compañía y sus accionistas, debiendo entenderse que el mismo no se realiza a favor de quien lo detenta, sino que debe hacerse a favor y en pro de los intereses de los terceros respecto de quienes existe tal deber. De esta forma, y como lo ha sostenido este Organismo y la doctrina, más que un derecho que se ejercita al arbitrio de los directores, constituye un deber que cede a favor de los accionistas de la compañía, debiendo el director ejercerlo en cuanto ello sea necesario y le permita realizar su labor de tal, cuestión que fue precisamente omitida en la especie".

Por lo anterior, la Superintendencia consideró que los directores: Juan Cúneo, Eduardo Bellinghausen, Juan Benavides, Alexander Fernández, Jaime Sinay, Gabriel Berczely, Pablo Lamarca y Ernesto Labatut habían infringido el artículo 39 de la Ley de Sociedades Anónimas,

“al no ejercer la facultad que dicho dispositivo establece respecto de los directores de una sociedad anónima para encontrarse plenamente informados de la marcha de la 
empresa, faltando a su deber fiduciario con la compañía y sus accionistas".

Por ello, aplicó a cada director la sanción de multa, a beneficio fiscal, ascendente a UF $300 .^{6}$

4. El mercado legal consideró que estos dictámenes marcaban un antes y un después en cuanto a gobiernos corporativos $^{7}$. En efecto, estas sanciones, sin perjuicio de los recursos pendientes a la fecha, precisan el papel de los directores en la sociedad anónima. La doctrina es conteste en que el artículo 41 de la Ley de Sociedades Anónimas establece el deber de diligencia y cuidado que pesa sobre los directores, en cuanto a que deben dedicar al ejercicio de sus funciones el cuidado y diligencia que los hombres deben emplear ordinariamente en sus negocios propios. Guillermo $\mathrm{Carey}^{8}$ precisa que la viola-

${ }^{6}$ Contra la resolución exenta $\mathrm{N}^{\circ} 859$, el director Pablo Lamarca interpuso recurso de reposición ante la misma Superintendencia de Valores y Seguros, el cual fue rechazado en todas sus partes mediante resolución exenta $\mathrm{N}^{\circ} 068$ de fecha 21 de enero de 2010. Además, todos estos directores dedujeron acción de reclamación en juicio sumario en contra de las resoluciones exentas $\mathrm{N}^{\circ} 854$, $855,859,860,861$, los que, a la fecha de este comentario, están aún tramitándose en primera instancia y acumulados o en proceso de acumulación ante el $24^{\circ}$ Juzgado Civil de Santiago bajo el rol C-1453-2010.

7 Por todos, véase las entrevistas a los abogados Pedro García y José Miguel Ried "FASA: Multa a Directores levanta", en Estrategia Santiago, de 6 de enero de 2010.

${ }^{8}$ Guillermo CAREY, De la sociedad anónima y la responsabilidad civil de los directores, Santiago, Editorial Universitaria, 1992, p. 141.

ción del deber de vigilancia o cuidado por parte de los directores puede ser consecuencia de su inactividad o de un desempeño negligente ${ }^{9}$.

En tal sentido, se enmarca la facultad del directorio de requerir información de los antecedentes y negocios sociales, lo que reviste también el carácter de deber para el director, a favor y en pro de los intereses de los accionistas de la compañía, como precisó la Superintendencia. Pero se presenta la duda de la extensión de dicho deber de obtener información social, al punto que podría llegarse al extremo que los directores se conviertan en revisores de todo lo que sucede en la compañía, o "investigadores", como señalaron los directores sancionados en sus descargos.

$\mathrm{Al}$ respecto, la Superintendencia precisó que este deber se extiende hasta las materias de relevancia o importancia para la compañía. Dada la vaguedad del concepto, resulta interesante volver a las formulaciones de cargos por la Superintendencia para determinar que la relevancia o importancia de un tema para su análisis por el directorio está dado por el concepto de información esencial que establece el artículo 9 de la Ley de Mercado de Valores:

"aquélla que un hombre juicioso consideraría importante para sus decisiones sobre inversión"),

${ }^{9}$ En el mismo sentido en el Derecho estadounidense Arthur R. Pinto y Douglas M. Branson, Understanding Corporate Law, Lexisnexis, 2004, p. 206. 
concepto que se puede considerar suficientemente internalizado en el mercado como para servir de parámetro a este respecto.

Sobre tales temas "esenciales", los directores tendrían que estar permanentemente informados y requiriendo antecedentes al respecto, sin que les basten los informes proporcionados por la administración. En efecto, en la doctrina extranjera se contempla una salvaguarda (safe harbor) para los directores que confían de buena fe en la información y reportes de sus subordinados ${ }^{10}$. Pero para dicha protección no basta la existencia de reportes de los subordinados, sino que la confianza en tales informes debe ser de buena fe, lo que implica en ciertas circunstancias para los directores un deber de averiguar mayor información (duty of inquiry) ${ }^{11}$. Siguiendo el

${ }^{10}$ La sección 141 (e) de la General Corporation Law del estado de Delaware dispone: "A member of the board of directors, or a member of any committee designated by the board of directors, shall, in the performance of such member's duties, be fully protected in relying in good faith upon the records of the corporation and upon such information, opinions, reports or statements presented to the corporation by any of the corporation's officers or employees, or committees of the board of directors, or by any other person as to matters the member reasonably believes are within such other person's professional or expert competence and who has been selected with reasonable care by or on behalf of the corporation". Texto obtenido de http:// delcode.delaware.gov/title8/c001/sc04/ index.shtml, revisado el 5 de mayo de 2011.

${ }^{11}$ Stephen M. Bainbridge, "Corporation Law and Economics”, Foundation Press, 2002, p. 291 criterio de la Superintendencia, en casos relevantes, el Directorio no puede limitarse a confiar en los informes y reportes de los subordinados, sin ciertas averiguaciones o confirmaciones.

En definitiva, mediante estos dictámenes, la Superintendencia de Valores y Seguros reforzó la obligación que tienen los directores de informarse sobre la marcha de la compañía, recalcando un papel activo al respecto, que no es absoluto, sino limitado al menos a lo que se calificaría como "información esencial" para efectos del mercado de valores. Pero este nivel de diligencia puede requerir directores profesionales que dediquen una cantidad de tiempo significativa a estas funciones y probablemente algún grado de especialización ${ }^{12}$, lo que puede ser finalmente el corolario necesario de estas exigencias.

\section{BibliografÍA}

Bainbridge, Stephen M., "Corporation Law and Economics", Foundation Press, 2002.

CARey, Guillermo, De la sociedad anónima y la responsabilidad civil de los directores, Santiago, Editorial Universitaria, 1992.

Clarke, Álvaro, "Ex Superintendentes analizan el fallo contra directores de Fasa", en El Mercurio, Santiago, 6 de enero de 2010.

García Pedro y José Miguel Ried "FASA: Multa a Directores levanta", en

${ }^{12}$ Álvaro ClaRKE, "Ex Superintendentes analizan el fallo contra directores de Fasa", en El Mercurio, Santiago, 6 de enero de 2010. 
Estrategia Santiago, de 6 de enero de 2010.

Pinto, Arthur R. and Douglas Branson, M., Understanding Corporate Law, Lexisnexis, 2004.

Puelma Accorsi, Álvaro, Sociedades, Santiago, Editorial Jurídica de Chile, 2009.

\section{Derecho De La Libre Competencia}

LO DETERMINANTE EN LA VENTA ATADA

Y EN LOS DESCUENTOS POR PRODUCTOS

EMPAQUETADOS COMO ABUSO DE POSICIÓN DOMINANTE DE EXCLUSIÓN. CORte Suprema, 14 de enero de 2011, ROL 2140-2010, $\mathrm{N}^{\mathrm{O}}$ IDENTIFICADOR Legal Publishing 47664.

La sentencia que comentamos trata de la compleja disciplina de las ventas atadas y los descuentos por productos empaquetados. En la venta atada, un monopolista o empresa con algún grado de poder de mercado vende su producto monopólico 'vinculante' a condición de que el comprador también compre algún otro -en principio competitivo- producto 'vinculado'. En los descuentos por productos empaquetados, un vendedor fija para un paquete o canasta de diferentes productos un precio inferior que la suma de los productos del paquete separadamente adquiridos ${ }^{13}$. La Corte expresa:

"[L]os contratos 'atados' obligan a quien desea adquirir un determinado bien o servicio a la adquisición de otros que no requiere necesariamente para poder celebrar la convención efectivamente deseada" (Cons. $5^{\circ}$ ).

En los últimos meses, estrategias de este tipo han estado presentes en la discusión pública a raíz de la práctica de gran parte de las instituciones crediticias del país de vincular el otorgamiento de créditos con seguros específicos asociados a los mismos, sin brindar mayores márgenes de elección al cliente ${ }^{14}$.

${ }^{13}$ Thomas A. Lambert, Appropriate Liability Rules for Tying and Bundled Discounting: A Response to professor Elhauge, Legal Studies Research Paper Series N ${ }^{\circ}$ 2011-04, University of Missouri School of Law, 2011, pp. 1-2. Una distinción recurrente sostiene que mientras que en el caso de las ventas atadas el cliente puede comprar las cantidades que quiera de uno u otro de los productos atados, en el caso de los descuentos por productos empaquetados las cantidades de cada producto que compone la canasta son fijas y las determina el vendedor. OECD, Fidelity and Bundled Rebates and Discounts, Competition Policy Roundtables Series, 2008, p. 7. El TDLC se refiere a venta atada explícita y vinculación implícita, para referirse con el último término al caso de los descuentos. TDLC, sentencia $\mathrm{N}^{\circ}$ 97/2010 (Voissnet II), de 4 de marzo de 2010, cons. $8^{\circ}$.

${ }^{14}$ El problema referido se ha estado discutiendo desde el punto de vista de la protección de los consumidores y de la 
El problema con estas estrategias de negocios es que ellas se presentan en un amplio rango de estructuras de mercado, desde mercados absolutamente monopólicos hasta otros altamente competitivos. Empresas en posición de dominio y sin posición de dominio las utilizan ${ }^{15}$. Y muchas veces se presentan como proconsumidores. Ni usted ni yo ignoramos lo que es un 'combo' en una cadena de comida rápida y bien sabemos que las cajas de regalo en perfumería suelen ser más convenientes que la compra separada de los componentes de las mismas.

El Derecho de la Libre Competencia viene abordando estas prácticas desde hace un buen tiempo como una categoría de abusos de posición dominante. Los reproches contra ellas se basan, principalmente, en tres líneas argumentales:

regulación (véase $\mathrm{SBIF}$, circulares $\mathrm{N}^{\circ} 3505$ de 22 de octubre de 2010 y N 3513 de 15 de noviembre de 2010; Proyecto de ley (mensaje del Ejecutivo) conocido como 'Sernac Financiero', Boletín No 7094-03, ingresado a la Cámara de Diputados el 3 de agosto de 2010, en esp., indicación del Ejecutivo en oficio $\mathrm{N}^{\circ}$ 533-358, de 3 de diciembre de 2010; Proyecto de ley (mensaje del Ejecutivo) que 'Moderniza y Fomenta la Competencia del Sistema Financiero', en Boletín No 7440-05, ingresado a la Cámara de Diputados el 13 de enero de 2011). En Europa, el asunto ha requerido de extensos estudios (véase Andrea RENDA (coord.), Tying and other potentially unfair commercial practices in the retail financial service sector, Bruselas, Center for European Policy Studies, 2009.

${ }^{15}$ Herbert Hovenkamp, Tying and the Rule of Reason: Understanding Leverage, Foreclosure and Price Discrimination, 2011, p. 26, en http:// ssrn.com/abstract $=1759552$, visitada el 7 de junio de 2011.
I) La posibilidad de discriminar precios y extraer un mayor excedente de los clientes;

II) El apalancamiento o traspaso del poder de mercado desde el mercado vinculante hacia un mercado competitivo -vinculado-(leverage);

III) El cierre o exclusión del mercado vinculado (market foreclosure).

En los últimos años, la tercera de las mencionadas es la línea de desarrollos predominante $y$, por tanto, estas prácticas son tratadas, principalmente, como abusos de exclusión ${ }^{16}$.

${ }^{16}$ En la perspectiva del derecho de la libre competencia, los reproches fundados en la explotación del cliente no permiten en principio y por sí solos fundar un reproche contra estas prácticas. Tampoco lo sería la afectación a la libertad de elección o libertad económica del cliente ni la interferencia en las elecciones de éste. La fijación de un precio excesivo al producto vinculante por el oferente con poder de mercado, podría ser una excepción que justificara un reproche a posteriori en este enfoque y a falta de regulación. En cambio, son más significativas las objeciones por los efectos de exclusión del mercado de competidores actuales o inhibición a competidores potenciales. Véase Blaise CARRON, Les transaction couplées en droit de la concurrence. Analyse économique et juridique comparé, Zürich, Ed. Schulthess, 2004, p. 406. Una perspectiva algo diferente en TDLC, sentencia $N^{\circ}$ 97/2010 (Voissnet II), de 4 de marzo de 2010: "[E]n relación con los consumidores [...] la restricción, explícita o implícita, de la libertad de los clientes para decidir si contratan telefonía y para determinar a su proveedor, tiende a afectar la libre competencia, pues altera el proceso de asignación de recursos basado en el mercado e impone barreras de entrada a proveedores 
En el caso, Voissnet S.A., (Voissnet) un proveedor de servicios de telefonía sobre internet (VoIP) reprochó a la demandada $\mathrm{TCH}$ la formulación de ofertas conjuntas o paquetes de servicios de telefonía fija y acceso a Internet de banda ancha por un único precio, por tener ellas el objeto y efecto de excluir competidores en el mercado de la telefonía fija. El TDLC consignó como requisitos para la configuración del ilícito, los siguientes:

i) que los productos o servicios incluidos en las ofertas conjuntas sean diferentes y no se vendan separadamente, en este caso, que $\mathrm{TCH}$ haya vendido el servicio de banda ancha sólo en forma empaquetada con el servicio minutos de tráfico de voz;

ii) que TCH tenga poder de mercado en el servicio que sólo vende en forma empaquetada, en este caso, la banda ancha;

iii) que la vinculación produzca o tienda a producir el efecto de inhibir el ingreso o de excluir competidores en el mercado del producto atado o potencialmente más competitivo, en este caso la telefonía, con o sin minutos de tráfico de voz y

de telefonía IP" (cons. 62\%). Pero luego, más en la línea de lo que indica la doctrina extranjera referida: "Es decir, lo que se objeta no es la paquetización en sí, sino que el diseño concreto de los paquetes de servicios ofrecidos por la demandada tengan un objeto exclusorio contrario a la libre competencia" (cons. 66 $6^{\circ}$.

iv) que dicha modalidad de comercialización carezca de una justificación o explicación alternativa al abuso de poder de mercado ${ }^{17}$.

El TDLC tuvo por acreditados los cuatro requisitos referidos ${ }^{18}$, impuso sanciones a la demandada y decretó medidas ${ }^{19}$. La Corte Suprema, con un

${ }^{17}$ TDLC, sentencia $\mathrm{N}^{\circ}$ 97/2010 (Voissnet II), de 4 de marzo de 2010, cons. $9^{\circ}$. La sentencia de la CS comentada (cons. $18^{\circ}$ ) brinda una nómina algo diferente: poder de mercado, abuso, ánimo anticompetitivo, efectos exclusorios. Nos inclinamos por la nómina del TDLC. En la orientación a los efectos que hoy rige en este sector normativo, la distinción entre los elementos 'abuso' y 'efectos' de la nómina de la CS, se difumina. El ánimo anticompetitivo -que la CS entiende presumirse, según veremos- tampoco agrega mucho donde lo reprobable no es excluir competidores y buscar ser monopolista, sino el valerse de medios ilegítimos para alcanzar o aproximarse a dicha situación, para mantenerla o, bien, explotar el monopolio en forma excesiva e ilegítima.

${ }^{18} \mathrm{Op}$. cit., cons. $73^{\circ}$. Sobre la acreditación de la venta atada (cons. $10^{\circ}$ a $23^{\circ}$ ), sobre la acreditación de la posición de dominio (Cons. $24^{\circ}$ a $56^{\circ}$, en esp. cons $35^{\circ}$ y ss.), sobre la exclusión o inhibición de competidores (cons. $57^{\circ}$ a $63^{\circ}$ ), sobre la ausencia de justificaciones alternativas (cons. $64^{\circ}$ a $72^{\circ}$ )

${ }^{19}$ En lo central, la parte dispositiva de la sentencia del TDLC (i) declara que la demandada infringió la letra b) del artículo $3^{\circ}$ delD.L. $N^{\circ} 211$, al condicionar contractualmente la venta de banda ancha a la contratación de servicio telefónico, atando comercialmente a dicha oferta conjunta un determinado número de minutos de tráfico de voz, con precios implícitos negativos para estos últimos; conducta apta para excluir competidores en el mercado de la telefonía; (ii) impone a TCH una multa de 5.000 UTA; (iii) ordena a TCH comercializar también por separado cada 
voto disidente, rechazó la reclamación contra la sentencia del TDLC.

\section{Elementos Para DaR} POR ESTABLECIDA LA POSICIÓN DE DOMINIO.

CALIFICACIÓN DEL SERVICIO

DE BANDA ANCHA COMO UN INSUMO ESENCIAL PARA LA PROVISIÓN DE TELEFONÍA IP

Es loable que la CS esté siendo más explícita en el último tiempo respecto a cómo se da por establecida la posición de dominio en un mercado ${ }^{20}$, cuestión fundamental para configurar un ilícito de abuso en sede de libre competencia. En el caso, la participación de mercado de la demandada en la prestación del servicio de banda ancha alámbrica ${ }^{21}$, su ventaja difícilmente replicable (ésta es, su red de pares de cobre,

uno de los servicios que integren sus ofertas conjuntas. Por consiguiente, y mientras TCH sea dominante en el servicio de banda ancha, no podrá atar a ésta ningún otro producto o servicio, debiendo, en consecuencia, mantener una oferta de banda ancha desnuda o naked. Asimismo, la demandada deberá establecer para sus ofertas conjuntas precios que no tengan por objetivo restringir la libre competencia y sean superiores, a lo menos, al precio de venta por separado del producto o servicio integrante de mayor valor. El TDLC efectúa, además, una recomendación de reforma regulatoria orientada en similar sentido.

${ }^{20}$ Véase CS, 17 de agosto de 2010, rol 1813-2010, cons. $12^{\circ}$.

${ }^{21}$ Las razones para descartar como sustituto del servicio de banda ancha inalámbrica se contienen en la sentencia del TDLC (n. 17), cons. $37^{\circ}$ a $41^{\circ}$. calificada de 'activo o insumo esencial' por ser económicamente poco viable de reproducir) y la barrera a la entrada fundada en los costos de duplicar dicha red, permiten tener por configurada su posición de dominio. $\mathrm{El}$ servicio mismo de banda ancha es calificado luego de insumo esencial para la provisión de telefonía IP, por ser indispensable para ésta (cons. $8^{\circ}$, $\left.9^{\circ}, 10^{\circ}\right)$.

\section{El efecto Anticompetitivo}

DETERMINANTE ES LA EXCLUSIÓN

O CIERRE DEL MERCADO

Y NO EL TRASPASO DE PODER DE MERCADO (LEVERAGE)

"En el contexto de la 'comercialización en forma atada', lo relevante es el riesgo de traspasar el poder de mercado que se tiene sobre un producto -banda ancha- a favor de otro -telefonía fija- respecto del cual no se detenta tal poder, pero que se podrá alcanzar mediante esta modalidad de comercialización" (cons. $6^{\circ}$ )

La lectura aislada de este considerando podría llevar a pensar que la CS adopta la teoría del leverage para recriminar las ventas atadas ${ }^{22}$. Un

${ }^{22}$ De la misma manera, si aisladamente leemos TDLC, sentencia $N^{\circ}$ 97/2010 (Voissnet II), de 4 de marzo de 2010 , cons. $59^{\circ}$ : "[L]a circunstancia de que el operador dominante de banda ancha condicione la venta de dicho servicio a la contratación de telefonía, le permite extender o potenciar su poder 
reproche a la práctica de las ventas atadas fundado únicamente en la circunstancia de evitar un supuesto traspaso de poder de mercado hacia un mercado hasta entonces competitivo sería insuficiente y se fundaría en una falacia. En efecto, el monopolista puede maximizar beneficios sin necesidad de vincular al producto monopólico otro expuesto a la competencia, sino que, para aquel propósito, basta que por el primer producto produzca a niveles monopólicos. De hecho, si a consecuencia de vincular el producto expuesto a la competencia cobrare por el paquete por sobre el precio monopólico, perdería ingresos y ya no estaría maximizando beneficios $^{23}$. Con todo, en los hechos, la estrategia comercial sí podrá llevar a un traspaso de poder de mercado desde uno menos competitivo a uno -hasta entonces- más competitivo. Pero ese traspaso no debiera reprocharse si no es como consecuencia de una exclusión anticompetitiva lograda en el mercado del producto vinculado $^{24}$. Afortunadamente, la

de mercado en éste último mercado, que es más competitivo, pues impide que los clientes decidan entre unos y otros oferentes de telefonía sobre la base de los méritos o características del servicio de cada uno".

${ }^{23}$ Esta crítica a la teoría del leverage se conoce como la "single monopoly profit theory". Véase LAMbert (n. 13), pp. 5-6. El problema con la teoría del leverage es que ésta ha justificado que la jurisprudencia en Estados Unidos brinde a la figura de la venta atada (tying) un injustificado tratamiento cuasi-per se, incluso hoy. Véase Hovenkamp (n. 15), p. 7.

24 "[E]s gracias a esos efectos [de exclusión] anticompetitivos, que el oferente puede sentencia comentada desarrolla unos cuantos razonamientos en torno a la exclusión $^{25}$, suficientes para entender que es en ella que la CS visualiza el efecto anticompetitivo, y lo anterior, aun cuando dichos razonamientos no sean lo suficientemente categóricos para esclarecer cuál es el estándar de exclusión.

3. El abUSO O ESTÁNDAR

DE EXCLUSIÓN O CIERRE

DEL MERCADO IMPLICA LA DIFÍCIL

TAREA DE CONFRONTAR PRECIOS CON COSTOS DEBIENDO

LA DEMANDADA ACREDITAR LOS SUYOS

La exclusión del mercado, por sí misma, no puede justificar la imposición

extender su poder sobre el mercado del producto vinculado y aumentar las barreras a la entrada en los mercados de los productos vinculante y vinculado" (traducido), CARRON (n. 16), p. 406.

${ }^{25}$ En la noción de exclusión entendemos obviamente comprendida la inhibición de entrada a un competidor potencial. La sentencia de la CS se hace cargo del punto, en el debate sobre la legitimación activa: "[E]1 agente económico puede participar actual o potencialmente en el mercado afectado por la conducta anticompetitiva de otro agente, la que normalmente apuntará a impedir que entren nuevos competidores, sean actuales o potenciales" (cons. $7^{\circ}$ ). Si, en cambio, nos apoyáramos en otros de los fundamentos del reproche contra las ventas atadas, deberíamos abrir no sólo la discusión de la legitimación activa en sede de libre competencia para otros segmentos de 'víctimas' (por ejemplo, clientes/consumidores) sino, además, plantear la cuestión de la extensión de la legitimación activa para iniciar subsecuentes demandas indemnizatorias. 
de responsabilidad al demandado. No toda exclusión es anticompetitiva. Una misión fundamental del Derecho de la Libre Competencia es la de deslindar exclusiones anticompetitivas de aquellas exclusiones que manifiestan una intensa competencia. La cuestión es debatida. Es claro que la propia ineficiencia del excluido o su insistencia en cobrar precios supracompetitivos no pueden fundar alegaciones de exclusiones anticompetitivas contra sus rivales. La superioridad competitiva del demandado debería también llevar a descartar alegaciones semejantes. Sobre esto último, expresa la CS:

"[E]1 eventual abuso de su posición de dominio [...] exige adicionalmente, que tales prácticas excluyentes no deriven de una eficiencia productiva o de innovación tecnológica-absolutamente válidos dentro de la libre competencia- sino que ellas tengan como fin conculcar la libre competencia" (cons. $6^{\circ}$ ).

La Corte esboza también una idea de anormalidad como criterio para precisar el estándar de abuso/ exclusión anticompetitiva:

"[E]1 abuso debe consistir en el empleo de métodos diferentes de aquéllos bajo los cuales puede darse una disputa normal entre empresas que ofrecen idénticos o similares bienes y servicios" (cons. $6^{\circ}$ ).
Sin embargo, más determinante es lo que sigue. Tres consideraciones adicionales de la sentencia de la CS tienen que ver con elementos que fundarían la existencia de una exclusión anticompetitiva. El contenido de dos de ellos (cons. $11^{\circ}$ y $13^{\circ}$ ), no resulta de un especial interés, ya que se podría aplicar igualmente a situaciones procompetitivas, del todo inocuas ${ }^{26}$. Detengámonos en el duodécimo:

"[B]asta apreciar los cuadros de correlación de precios entre los distintos productos que ofrece la demandada para advertir claramente que el servicio telefónico dentro de sus ofertas conjuntas tiene un valor inferior a su costo, el cual incluye además una cierta cantidad de minutos de tráfico de voz" (cons. $12^{\circ}$ ).

De esta manera, la CS coloca sobre la mesa la necesidad de confrontar los precios que cobra la demandada con sus costos, infiriendo que, en el caso, los precios están por debajo de los costos. La primera parte del razonamiento es importante, sin embargo, no había razones determinantes para efectuar la inferencia indicada.

En efecto, entender que resulta necesario confrontar los precios que cobra la demandada con sus cos-

${ }^{26}$ Por ejemplo, a la existencia de un servicio de 'menú del día' y un servicio 'a la carta' en muchos restoranes. 
tos brinda un umbral preciso para establecer cuándo hemos salido de una exclusión legítima y entrado al terreno de una exclusión anticompetitiva $^{27}$. Esto resulta más importante aún, teniendo en cuenta que el TDLC pareció entender que extender la discusión a los costos no resultaba procedente en relación con la figura de las ventas atadas ${ }^{28}$.

En cambio, sostener que la correlación entre dos diferentes estructuras de precios, una por los servicios conjuntos y otra por los mismos servicios separados "permite advertir claramente" que uno de los servicios dentro del paquete está siendo prestado por debajo de sus costos, sin otros antecedentes de los mismos,

${ }^{27}$ Así, se sostiene que el siguiente test asegura un umbral de licitud: Si el precio descontado del producto expuesto a la competencia es igual o superior al costo para la empresa y esto es así incluso cuando el total del descuento es atribuido a dicho producto, entonces cualquier vendedor igualmente eficiente de ese producto debería poder otorgar el mismo descuento. Con esto, sólo serían excluidos (i) los vendedores menos eficientes que el vendedor de productos paquetizados y (ii) los vendedores igualmente eficientes, pero no dispuestos a vender al costo. Véase Lambert (n. 13), p. 61.

${ }^{28}$ TDLC, sentencia N ${ }^{\circ}$ 97/2010 (Voissnet II), de 4 de marzo de 2010: "[E]n cuanto a la racionalidad económica o de costos de las ofertas conjuntas que alega TCH basada en que los costos de los paquetes se cubrirían con sus precios, este Tribunal considera que tal alegación corresponde a una defensa propia de la imputación de prácticas predatorias implícita en la demanda de Voissnet, pero no justificaría en modo alguno efectuar una venta atada con las características de la de autos, ya analizadas" (cons. $68^{\circ}$ ). carece de fundamento. De hecho, es una afirmación que el TDLC no estuvo en condiciones de efectuar ${ }^{29}$. En realidad, la correlación entre las diferentes estructuras de precios es una mera aproximación, pero no dice algo definitorio sobre si los precios se encuentran por encima o por debajo de los $\operatorname{costos}^{30}$. La propia CS reconoce que la demandada no aportó evidencia sobre sus costos:

"[L]a demandada no demostró el costo de proveer cada servicio por separado, la determinación precisa que hizo respecto de los costos compartidos ni la entidad de los beneficios económicos que le acarrea empaquetar sus productos y que le permitían financiar, en su

${ }^{29}$ Por lo demás, los razonamientos del TDLC sobre la exclusión (cons. $57^{\circ}$ a $63^{\circ}$ ) se refieren en términos generales a la existencia de una exclusión en los hechos, pero no brinda elementos para diferenciar entre una exclusión procompetitiva de una anticompetitiva.

${ }^{30}$ Consideremos el siguiente ejemplo. Un 'menú del día' compuesto de plato de fondo $(\mathrm{PF})$ y entrada o postre $(\mathrm{EoP})$ y bebida $(\mathrm{B})$ tiene un precio de $\$ 6.000$. Los precios de productos equivalentes, 'a la carta', tienen los siguientes precios: PF: \$7.000; EoP: \$3.000; B: \$2.000. Siendo así, los precios implícitos en el paquete ('menú del día'), serían los siguientes: $\mathrm{PF}+\mathrm{EoP}$ : \$4.000; PF + B: \$3.000; EoP + B: \$-1.000. ¿ La circunstancia que el precio implícito de EoP + B sea negativo, significa que, en el paquete, EoP o B, se encuentran bajo el costo? No. Se trata cuando mucho de una aproximación de esto último y que la supuesta pérdida podría encontrarse subsidiada por los ingresos por $\mathrm{PF}$. Pero no es posible afirmar categóricamente que existan precios bajo los costos. 
concepto, las tarifas más bajas de sus planes" (cons. 14\%).

Lo que ocurre en un caso como este, desde el punto de vista de la organización industrial, es que la demandada integrada verticalmente en los segmentos de banda ancha y telefonía tiene dos opciones para protegerse de la entrada de un rival no integrado que requiere, para poder competir en uno de esos mercados (telefonía), del insumo (banda ancha) de propiedad de la demandada. La demandada puede ya sea bloquear el acceso del insumo ${ }^{31} \mathrm{o}$, bien, brindar el acceso al insumo pero cobrar precios predatorios en el segmento minorista (que para los efectos de esta causa, era la telefonía ${ }^{32}$. Pero para poder aplicar el test de exclusión predatoria, era necesario tener a la vista los costos de los distintos productos componentes de la canasta.

Si no hay confrontación de precios con costos, ¿con qué criterio nos podemos quedar para distinguir entre una exclusión procompetitiva y una exclusión anticompetitiva? ${ }^{33}$. ¿O es

${ }^{31}$ Esta modalidad de la estrategia ya había sido discutida entre las mismas empresas y ante la misma sede, con condena anterior de la demandada: TDLC, sentencia $\mathrm{N}^{\circ} 45 / 2006$ (Voissnet I), de 26 de octubre de 2006, Reclamación rechazada en parte y acogida en otra, por CS 4 de julio de 2007, rol 6236-06.

${ }^{32}$ OECD, Margin Squeeze, Competition Policy Roundtables Series, 2009.

${ }^{33} \mathrm{La}$ OECD da cuenta de la convergencia en el tratamiento de diferentes tipos de abusos de exclusión: ventas atadas, descuentos por productos empaquetados, descuentos por fidelización, y predación. OECD (n. 13), p. 11. que se trata de un asunto de carga de la prueba y, por tanto, una vez acreditada la posición dominante y la exclusión o cierre de mercado en los hechos, correspondía a la demandada acreditar que su eficiente estructura de costos le permitía cobrar semejantes precios bajos por el paquete?

\section{Cuestiones probatorias} Y AUSENCIA DE UNA EXPLICACIÓN ALTERNATIVA

Si bien hoy los elementos subjetivos tienden a excluirse del análisis de casos de libre competencia y, por tanto, se aparta de la corriente principal el que la CS haya considerado la intención o el ánimo anticompetitivo entre los requisitos del abuso de posición dominante ${ }^{34}$, la circunstancia que ésta sea presumida a partir de encontrarse acreditada una exclusión en los hechos, es una primera cuestión probatoria digna de relevar.

"[D]e la anterior constatación es posible presumir la intención de [TCH] de evitar la adquisición por parte de los consumidores de los servicios por separado [...]" (cons. $\left.11^{\circ}\right)$.

"[L]o anterior evidencia un ánimo anticompetitivo, porque resulta inexplicable que el precio de ambos productos, al ser vendidos en la forma de un paquete, sea inferior al precio

\footnotetext{
${ }^{34}$ Véase (n. 17).
} 
de alguno de sus componentes si son vendidos por separado, lo cual permite descartar la racionalidad económica del precio del producto o servicio que se ata" (cons. 13 ${ }^{\circ}$.

Lo anterior puede entenderse como una interesante manifestación de una mayor precisión sobre la atribución de la carga de la prueba durante el juicio antimonopolios. Socava aquella afirmación general de que 'corresponde al demandante acreditar el ilícito y sus elementos', y la sustituye por un traspaso dinámico al demandado de la carga de demostrar una causal de justificación, cuando hechos en principio ilícitos ya constan en el proceso. Esta idea, que la CS ya había recogido anteriormente $^{35}$ se consigna acá en relación con la necesidad en que se encontró la demandada de acreditar sus costos efectivos si pretendía fundar en ellos su defensa, según referimos en la sección anterior (cons. $14^{\circ}$ ). Es el demandado quien se encuentra en posesión de dicha información y, por tanto, a él asigna la CS la carga de probar dichos costos y el hecho de encontrarse por debajo de los precios cobrados. ¿De haber rendido tal prueba, habría mantenido el TDLC su afirmación de que la discusión no debe extenderse a la confrontación de costos con precios tratándose de las ventas atadas? ${ }^{36}$.

${ }^{35}$ CS, 2 de junio de 2010, rol 277-2010, cons. $21^{\circ}$.

${ }^{36}$ Véase (n. 28).

${ }^{37}$ TDLC, sentencia $N^{\circ}$ 97/2010 (Voissnet II), de 4 de marzo de 2010, (cons. $64^{\circ}$ a $72^{\circ}$ ). sólo pueden entonces explicarse a la luz del propósito perseguido por la demandada de proteger o consolidar su posición en el mercado de la telefonía fija -altamente competitivo por el arribo de nuevas tecnologías- a partir del abuso de su poder de mercado en el mercado de la banda ancha" (cons. 15\%).

"[L]o expuesto conduce inevitablemente a concluir que [TCH] optó por no comercializar su servicio de banda ancha de manera separada, sino que atándola con su servicio de telefonía fija para dificultar el desarrollo de servicios por parte de sus competidores, que deben utilizar su red" (cons. 16 $6^{\circ}$.

En cuanto al establecimiento del cuarto requisito de la figura, esto es, 'ausencia de una explicación alternativa', el TDLC, había descartado una a una las explicaciones o defensas que la demandada había dado para su conducta. La demandada invocó razones comerciales, económicas, normativas y técnicas que no prosperaron ${ }^{37}$. La CS también recoge esta idea de falta de explicación alternativa:

"[L]as conductas denunciadas

durante el juicio antimonopolios.
Socava aquella afirmación general
de que 'corresponde al demandante
acreditar el ilícito y sus elementos',
y la sustituye por un traspaso diná-
mico al demandado de la carga de
demostrar una causal de justificación,
cuando hechos en principio ilícitos
ya constan en el proceso. Esta idea,
que la CS ya había recogido anterior-
mente ${ }^{35}$ se consigna acá en relación
con la necesidad en que se encontró
la demandada de acreditar sus cos-
tos efectivos si pretendía fundar en
ellos su defensa, según referimos en
la sección anterior (cons. 14 ${ }^{\circ}$ ). Es el
demandado quien se encuentra en
posesión de dicha información y, por
tanto, a él asigna la CS la carga de
probar dichos costos y el hecho de
encontrarse por debajo de los precios
cobrados. ¿d De haber rendido tal
prueba, habría mantenido el TDLC
su afirmación de que la discusión no
debe extenderse a la confrontación
de costos con precios tratándose de
las ventas atadas?




\section{LAS MEDIDAS O REMEDIOS}

La CS (cons. $17^{\circ}$ ) comparte las medidas impuestas por el TDLC. El voto disidente objeta que se imponga una multa. La consecuencia más sensible para la comunidad ha sido la existencia hoy de ofertas de banda ancha desnuda por parte de la demandada. Para evitar la asimetría regulatoria, el TDLC recomendó al regulador de telecomunicaciones que la obligación de ofrecer separadamente los servicios integrantes de un paquete se extienda vía regulación de las ofertas conjuntas a todos los actores de la industria. La CS, a diferencia de otras oportunidades, no reprueba que una recomendación sea emitida a propósito de un procedimiento contencioso.

\section{SíNTESIS}

Resumimos el análisis en la siguiente regla extractada:

Una empresa integrada verticalmente, que vincula o paquetiza los productos de sus segmentos integrados, con posición dominante en uno de ellos, y que excluye o inhibe en los hechos a un rival actual o potencial no integrado, y constando en autos un indicio o aproximación de que pueda estar vendiendo bajo los costos, incurre en una exclusión anticompetitiva (abuso de posición dominante) cuando no justifica la situación en su eficiencia productiva (bajos costos, innovación tecnológica, etc.) ni en otra razón pro-mercado.

Si ésta es una conclusión consciente y sustantiva o por el contrario constituye una adecuación a las limitaciones procesales que se encuentra dentro de las reglas del juego probatorio, es algo que futuras decisiones sobre abusos de posición dominante de exclusión deberían esclarecer.

\section{BibliografíA}

CARron, Blaise, Les transaction couplées en droit de la concurrence. Analyse économique et juridique comparé, Zürich, Ed. Schulthess, 2004

Hovenkamp, Herbert, Tying and the Rule of Reason: Understanding Leverage, Foreclosure and Price Discrimination, 2011, http://ssrn.com/abstract=1759552

LAmbert, Thomas A., Appropriate Liability Rules for Tying and Bundled Discounting: A Response to professor Elhauge, Legal Studies Research Paper Series $\mathrm{N}^{\circ}$ 2011-04, University of Missouri School of Law, 2011

OECD, Fidelity and Bundled Rebates and Discounts, Competition Policy Roundtables Series, 2008.

OECD, Margin Squeeze, Competition Policy Roundtables Series, 2009.

RendA, Andrea (coord.), Tying and other potentially unfair commercial practices in the retail financial service sector, Bruselas, Center for European Policy Studies, 2009. 